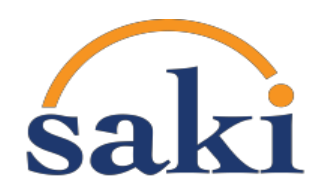

\title{
Pengaruh Besaran Initial Return Terhadap Performa Jangka Panjang Saham Perusahaan
}

\author{
Gavin Adrian, Michael Adityakrisna Rahardja, Aulia Nurul Huda *) \\ Sekolah Bisnis dan Ekonomi - Universitas Prasetiya Mulya \\ BSD City Kavling Edutown I.1 , Jl. BSD Raya Utama, BSD City, Tangerang 15339
}

\section{Keywords:}

initial return, buy and hold, market overreaction, in itial public offering (IPO), Indonesia

\section{Kata Kunci:}

initial return, buy and hold, market overreaction, penawaran umu merdana, Indonesia

\section{* Corresponding author: aulia.nurul@pmbs.ac.id}

\begin{abstract}
Abstrak
Penelitian ini bertujuan untuk mencari tahu hubungan besarnya initial return saat perusahaan melakukan penawaran umum terbuka terhadap performa jangka panjang saham perusahaan yang diukur menggunakan buy and hold return pada Bursa Efek Indonesia. Penelitian sebelumnya berargumen bahwa initial return bernilai positif karena adanya market overreaction dan perusahaan yang mengambil windows of opportunity dan hal ini yang menyebabkan performa jangka panjang yang buruk. Menggunakan metode cross-sectional regression, penelitian ini menemukan adanya hubungan negatif yang signifikan antara initial return dengan buy and hold return selama 3 tahun setelah melakukan penawaran umum terbuka. Hal ini sejalan dengan penelitian sebelumnya di negara-negara lain yang menyatakan terjadi market overreaction sehingga harga yang terbentuk di hari pertama perdagangan menjadi terlalu tinggi dan seiring berjalannya waktu harga ini akan terkoreksi. Penelitian ini juga menemukan bahwa diperlukan 3 tahun sampai harga tersebut terkoreksi, diindikasikan dengan koefisien initial return yang tidak bernilai signifikan pada buy and hold return selama 1 tahun dan 2 tahun.

\section{Sari Pati}

This research attempts to find relationship between initial return when IPOs with long term performance of company's stock with buy and hold return as the indicator at Indonesian Stock Exchange. Previous researches argue that positive initial return occur due to market overreaction and companies taking windows of opportunity and this is also the cause of poor long-term performance. Using cross-sectional regression method, this research finds a significant negative relationship between initial return with three years buy and hold return. This finding is in line with previous researches in various markets that state market overreaction as a cause of positive initial return and therefore the price shaped on the first trading day is too high. This "wrong" price would be adjusted as time goes on. This research also finds that it needs 3 years for the price to be corrected, indicated by the non-significant coefficient of initial return when being regressed to buy and hold return for 1 year and 2 years.
\end{abstract}




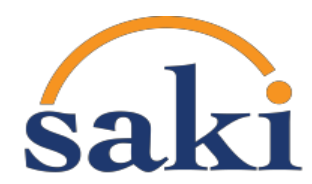

\section{Pendahuluan}

Initial Public Offering atau yang sering disingkat sebagai IPO merupakan satu peristiwa kepemilikan perusahaan tertutup ditawarkan kepada publik. Hal ini dilakukan oleh perusahaan untuk mencari dana tambahan. Dalam pasar modal, hal yang lazim dilakukan adalah saham perusahaan ini ditawarkan terlebih dahulu oleh underwriter dan baru kemudian diperdagangkan secara terbuka pada bursa. Salah satu tugas terbesar underwriter dalam proses IPO ini adalah, bersamaan dengan perusahaan, menentukan harga atau yang biasa disebut sebagai offer price. Menurut Suyatmi dan Sujadi (2006), penentuan harga merupakan hal yang perlu dilakukan dengan hati-hati karena perusahaan ingin menetapkan harga yang dapat memberikan initial return kepada investor agar menarik minat para investor, namun di sisi lain perusahaan ingin mendapatkan dana sebanyak-banyaknya agar dapat digunakan untuk kepentingan perusahaan. Fenomena initial return bernilai positif dapat ditemukan di berbagai negara. Hal ini didokumentasikan oleh Ibbotson, Sindelar, dan Ritter (1988) pada pasar Amerika Serikat, Chorruk dan Worthington (2010) pada pasar Thailand, Vong dan Trigueiros (2010) pada pasar Hong Kong, dan masih banyak lainnya.

Initial return, yang diukur dengan membandingkan harga penutupan di hari perdagangan pertama dengan offer price, juga dapat diamati dalam pasar Indonesia. Mengambil data dari perusahaan yang melakukan IPO dari tahun 1992 sampai dengan 2006, dari 382 perusahaan yang dapat diamati, 310 perusahaan memiliki initial return yang bernilai positif. Banyaknya perusahaan yang memiliki initial return yang positif memunculkan pertanyaan mengapa fenomena ini dapat terjadi. Sekilas, hal ini dapat terjadi karena market overreaction (Ritter, 1991).

Mengetahui hal ini, banyak peneliti yang menjadi tertarik dalam mencari tahu lebih jauh tentang efek initial return yang disebabkan oleh market overreaction terhadap performa jangka panjang perusahaan dengan harga saham jangka panjang sebagai indikator. Ritter (1991) menemukan bahwa semakin besar initial return perusahaan, semakin buruk performa jangka panjang perusahaan yang diukur 
menggunakan pertumbuhan harga saham selama 3 tahun setelah perusahaan melakukan IPO. Peneliti mengungkapkan terdapat 2 penje lasan terhadap hal ini: investor yang overoptimistic dan juga perusahaan yang mengambil keuntungan dari "windows of opportunity". "Windows of opportunity" didefinisikan sebagai periode di saat perusahaan yang melakukan IPO selalu mendapat hasil yang baik dan berhasil melakukan IPO dengan harga penawaran yang tinggi dan menimbulkan initial return dengan tingkat tertentu. Hal ini bisa terjadi saat kondisi ekonomi sedang baik atau kondisi market yang sedang optimis, dan lain lain.

Hasil dari penelitian terdahulu yang mendokumentasikan hubungan yang terbalik antara initial return dengan performa jangka panjang perusahaan menjadi menarik untuk dilakukan di Bursa Efek Indonesia terutama karena perbedaan karakteristik pasar -- sebagian besar penelitian terdahulu dengan topik yang sama dilakukan di negara maju. Penelitian ini akan memberikan manfaat bagi investor agar dapat menambahkan satu aspek pertimbangan dalam keputusan investasi terutama dalam perusahaanperusahaan yang baru melewati proses IPO serta mencoba membuktikan adanya fenomena overreaction pada IPO juga terjadi di Bursa Efek Indonesia. Oleh karena itu, pada penelitian ini, penulis akan menyelidiki hubungan besarnya initial return terhadap performa jangka panjang perusahaan yang diukur menggunakan pertumbuhan harga saham 3 tahun setelah melakukan IPO.

\section{Kajian Pustaka dan Pengembangan Hipotesis}

\section{Faktor-faktor yang Memengaruhi Initial Return dan Performa Jangka Panjang}

Menurut De Bondt dan Thaler (1987) yang meneliti mengenai market behavior dari investor, terjadi overreaction di capital market, terutama pada saat banyak terjadi peristiwa keuangan di suatu negara atau di dunia. Market overreaction tidak hanya terjadi pada peristiwa seperti IPO (Ritter, 1991), atau SEO (Wadhwa et al., 2016), namun juga ketika terdapat informasi baru yang beredar di publik mengenai suatu saham atau perusahaan. 


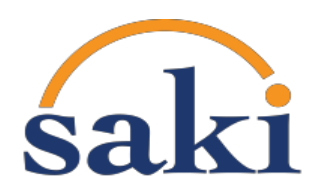

Market overreaction sendiri berarti fenomena saat investor cenderung memiliki reaksi berlebihan pada peristiwa atau informasi baru yang tidak terduga dan lebih memprioritaskan informasi tersebut dalam pengambilan keputusan daripada melihat data historis atau data yang selama ini telah ada. Maka dari itu, satu peristiwa atau informasi seperti laporan earnings tahunan yang baik dari perusahaan akan memberi lonjakan harga dari suatu saham. Karena adanya perbedaan antara harga wajar suatu saham dengan harganya di pasar, setelah beberapa waktu harga akan kembali menyesuaikan ke nilai wajarnya setelah informasi lain tersebar secara merata dan investor sudah kembali berpikir secara rasional. Dengan begitu, Ritter (1991) berpendapat bahwa dengan harga dasar saham yang mencerminkan bias dari optimisme atau pesimisme berlebih dari investor, saham-saham yang terlihat tidak menarik justru merupakan pilihan investasi yang lebih menarik daripada saham yang sekarang terlihat menarik.

Sesuai dengan penelitian Ritter (1991) yang melakukan penelitian mengenai overreaction hypothesis, beberapa peneliti lain telah melakukan penelitian di berbagai negara dan mendapat kesimpulan yang sama. Sehgal dan Singh (2008), dan penelitian Boussaidi (2013) menemukan bahwa hal tersebut terjadi pada sepertiga sampel yang dite liti di India dan Tunisia.

Juga mendukung hal tersebut, menurut penelitian yang dilakukan oleh Jai dan Kini (1994), underperformance yang terjadi pada perusahaan yang melakukan IPO disebabkan oleh adanya asymmetric information yang beredar di market membuat investor menjadi overoptimistic terhadap performa jangka panjang perusahaan tersebut. Hal ini dibuktikan negatif oleh Jai dan Kini (1994), dengan hasil dari penelitian menunjukkan bahwa adanya peningkatan sales dan capital expenditure setelah tahap IPO hanyalah peningkatan sesaat yang tidak dapat dipertahankan perusahaan, sehingga mengakibatkan penurunan kinerja jangka panjang dari perusahaan tersebut dan tentunya, hal ini juga mem engaruhi kinerja jangka panjang saham dari perusahaan tersebut.

\section{Issue Size}


Ukuran dari penawaran ditentukan dari banyaknya jumlah saham yang diterbitkan dan harganya saat IPO. Variabel ini digunakan di penelitian sebelumnya untuk mengontrol risiko (termasuk risiko underperformance) dari perusahaan yang melakukan IPO dan ketidakpastian dari penerbit saham. Perusahaan yang sudah lebih mapan dan dewasa seringkali melakukan IPO dengan ukuran penawaran yang lebih besar dan secara umum memiliki risiko yang lebih kecil daripada perusahaan dengan ukuran penawaran yang lebih kecil (Guo, Lev, dan Shi, 2006). Terdapat penelitian yang menemukan bahwa ukuran IPO yang besar akan mengurangi tingkat underperformance jangka panjang dari suatu perusahaan (Corhay, dkk. 2002). Di Indonesia, hasil penelitian dari Mahardhini dan Agus (2009) juga mengungkapkan bahwa issue size adalah satu-satunya variabel yang signifikan yang memberikan pengaruh pos itif terhadap performa jangka panjang sesudah IPO dari perusahaan-perusahaan di Indonesia yang IPO dari tahun 2000 hingga tahun 2005.

\section{Growth Expectation}

Growth expectation merupakan ekspektasi pertumbuhan pasar terhadap suatu saham perusahaan tertentu. Seringkali, hal ini dapat diukur dengan menggunakan market ratios seperti price-to-earnings, market-to-book, dan lain-lain. Pada umumnya, investor rela membayarkan premium yang lebih besar ketika memiliki ekspektasi pertumbuhan yang tinggi terhadap saham perusahaan, menjadikan market ratios yang disebutkan semakin besar. Berdasarkan Zheng dan Stangeland (2007), ketika penutupan hari pertama perdagangan, rasio-rasio ini seharusnya merefleksikan ekspektasi pertumbuhan investor (terhadap saham tertentu). Jika rasio ini sudah merefleksikan seluruh informasi terkandung pada initial return, maka koefisien dari initial return akan bersifat tidak signifikan.

\section{Wealth Relative}

Wealth relative merupakan proxy yang digunakan oleh Ritter (1991) untuk membandingkan performa saham dengan performa benchmark, dalam kasus Ritter, saham perusahaan dari industri dan 


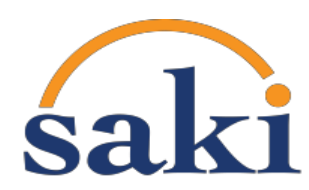

market value yang mirip. Wealth relative ini merupakan hasil perhitungan dengan rumus $(1+$ average return saham-saham IPO selama 3 tahun) / (1+ average return dari benchmark). Sehingga, ketika nilai dari wealth relative kurang dari 1 , average return dari benchmark yang digunakan lebih besar dibandingkan dengan average return saham-saham IPO selama 3 tahun. Ritter juga menggunakan wealth relative untuk menentukan dummy variable dari industri ketika melakukan analisis regresi.

\section{Debt-to-Equity Ratio}

Menurut Firth dan Smith (1992), tingkat kewajiban yang tinggi akan mempersulit pihak manajemen perusahaan dalam melakukan prediksi perusahaan di masa depan. Menurut hasil dari penelitian lain di Italia oleh Pagano, dkk. (1998), perusahaan melakukan go public bukan untuk membiayai ekspansi dan pertumbuhan di masa depan, namun untuk menyeimbangkan akun mereka setelah melakukan investasi jangka panjang yang tinggi untuk ekspansi dan pertumbuhan di masa depannya. Degeorge dan Zeckhauser (1993) juga beranggapan bahwa pengurangan rasio utang adalah salah satu alasan perusahaan melakukan IPO. Penelitian ini juga akan melihat apakah hal yang sama terjadi juga pada perusahaan-perusahaan di Indonesia.

\section{Hubungan Initial Return dengan Performa Saham Jangka Panjang}

Salah satu peristiwa saat market overreaction paling sering terjadi adalah ketika perusahaan melakukan proses IPO. Ritter (1991) meneliti performa jangka panjang perusahaan yang melakukan IPO dan menemukan bahwa terdapat hubungan yang negatif antara besarnya initial return dengan return harga saham perusahaan tiga tahun setelah melakukan IPO. Peneliti berargumen bahwa adanya initial return pada hari pertama perdagangan disebabkan oleh market overreaction. Dengan demikian, harga yang terbentuk di hari pertama kurang mencerminkan nilai fundamental dari perusahaan tersebut. Oleh karena itu, Ritter juga menemukan bahwa dalam jangka waktu 3 tahun setelah IPO, harga saham perusahaan-perusahaan ini akan terkoreksi dan kembali ke nilai wajarnya. Lebih jauh lagi, peneliti juga 
mengungkapkan bahwa ketika membandingkan perusahaan-perusahaan ini dengan perusahaan sejenis (dilihat dari ukuran dan industrinya), saham perusahaan yang melakukan IPO tidak menunjukkan performa yang lebih baik dibandingkan dengan saham perusahaan sejenis. Hal ini ditunjukkan dengan membandingkan BHR (buy and hold return) kedua kelompok. Kelompok yang melakukan IPO memiliki BHR sebesar 34.47\% dan kelompok pembanding (yang terdiri dari perusahaan listed pada industri yang sama dan memiliki market value yang mirip) memiliki BHR sebesar $61.86 \%$.

Menurut Raharja, Suhaeli, dan Mranani (2017), harga saham yang berada di atas intrinsic valuenya membutuhkan waktu yang cukup lama untuk kembali terkoreksi mendekati intrinsic value dari saham tersebut karena adanya informasi asimetris yang ada di pasar. Hal yang sama terjadi juga dengan fenomena market overreaction saat IPO. Sesuai dengan penelitian dari Ritter (1991) pula, efek underperformance setelah IPO baru terlihat dari pengukuran buy and hold returns (BHR) efek dengan jangka periode 3 tahun sejak perusahaan IPO.

\section{Signalling Theory}

Namun, di sisi lain, terdapat penelitian yang mengatakan bahwa initial return yang terjadi merupakan underpricing yang dilakukan oleh perusahaan sebagai sinyal yang diberikan oleh perusahaan kepada pasar. Teori ini dikenal sebagai signalling theory. Allen dan Faulhaber (1989), Welch (1989), dan Grinblatt dan Hwang (1989) berpendapat bahwa semakin besar underpricing yang dilakukan, semakin baik kualitas perusahaan tersebut. Hal ini dikarenakan underpricing yang dilakukan merupakan upaya memberi sinyal kepada investor. Fenomena underpricing yang besar ini hanya dapat dilakukan oleh perusahaan yang memiliki kualitas yang baik karena mereka merasa dapat menutup biaya underpricing di masa yang akan datang.

Sebaliknya, perusahaan yang tidak memiliki kualitas baik harus mengeluarkan dana untuk mengimitasi signalling yang dilakukan oleh perusahaan berkualitas baik dan perusahaan juga perlu mengeluarkan biaya untuk mengimitasi sumber daya yang mereka miliki agar menyerupai yang dimiliki 
oleh perusahaan berkualitas baik (Welch, 1989). Efek dari biaya yang lebih tinggi ini membuat alternatif yang dimiliki oleh perusahaan berkualitas kurang baik sangat menarik -- menunjukkan nilai asli dari perusahaan tersebut. Menurut Welch (1989), perusahaan berkualitas baik berani melakukan underpricing karena mereka percaya bahwa mereka dapat menutup cost of underpricing ini dengan mendapatkan favourable terms pada seasoned equity offerings.

\section{Metode Penelitian}

\section{Populasi dan Sampel Penelitian}

Penelitian ini akan mengambil populasi seluruh perusahaan yang melakukan penawaran umum perdana pada Bursa Efek Indonesia dan memenuhi beberapa kriteria yang sudah ditentukan. Kriteria ini adalah perusahaan melakukan penawaran umum perdana di antara tahun 2004 dan 2014. Batas bawah tahun digunakan karena dari periode 2004, pertumbuhan ekonomi Indonesia sedang dalam masa yang stabil dengan pertumbuhan per tahun di atas 5\%. Satu-satunya tahun pada periode ini pertumbuhan ekonomi tidak mencapai 5\% adalah pada tahun 2009 yaitu sebesar $4.63 \%$ karena dampak krisis keuangan dunia yang disebabkan krisis subprime mortgage di Amerika Serikat. Pada tahun 2010 pertumbuhan ekonomi Indonesia kembali naik ke $6.22 \%$ dan stabil di level di atas 5\% pada tahun-tahun berikutnya. Sedangkan batas atas periode adalah tahun 2014, karena penulis ingin meneliti performa perusahaan setelah 3 tahun melakukan penawaran umum perdana.

Sampel penelitian dipilih dari 11 Industri berbeda menurut Global Industry Classification Standard (GICS).

\section{Data dan Sumber Data}

Data yang diperlukan adalah data sekunder yang diperoleh melalui dua sumber, yaitu Bloomberg Terminal dan Yahoo! Finance sebagai pelengkap berdasarkan data yang ada pada tahun 2018 terhadap perusahaan-perusahaan yang IPO sejak tahun 2004 hingga 2014 ..

\section{Teknik Pengumpulan Data}




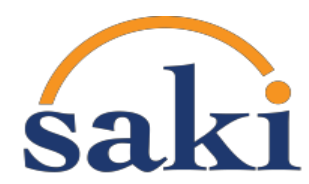

Sampel untuk penelitian ini diambil dengan menggunakan metode purposive sampling dengan menetapkan beberapa kriteria yang dalam pengambilan sampel seperti yang sudah dijelaskan di atas. Kriteria tersebut diantaranya adalah perusahaan yang IPO dari tahun 2004 hingga 2014 dengan data yang tersedia di Bloomberg Terminal atau Yahoo! Finance. Data yang sudah didapat akan diolah sebagaimana yang diperlukan agar data sesuai dengan kebutuhan penelitian.

\section{Definisi Operasional}

Pengoperasionalan konsep atau disebut dengan mendefinisikan konsep secara operasi adalah menje laskan karakteristik dari objek ke dalam elemen-elemen yang dapat diobservasi yang menyebabkan konsep dapat diukur dan dioperasionalkan di dalam riset (Sekaran, 2006). Konsep operasional yang perlu dije laskan dalam penelitian ini adalah:

a) Initial return sebagai variabel independen merupakan persentase perbedaan harga penutupan di hari perdagangan pertama suatu perusahaan dengan offer price saham tersebut.

b) Performa jangka panjang sebagai variabel dependen merupakan return dari saham suatu perusahaan diukur menggunakan holding period return atau pertumbuhan harga saham penutupan hari pertama sampai 3 tahun setelah IPO dengan formula sebagai berikut:

$$
B H R i_{36}=\prod_{t=1}^{36}\left(1+r_{i t}\right)
$$

$B H R i_{36}$ adalah buy and hold return dari harga saham perusahaan $i$ selama 36 bulan setelah perusahaan IPO. $r_{i t}$ adalah return mentah perusahaan $i$ di bulan $t$. Metode ini mengukur total return dimana saham dibeli di harga penutupan pertama setelah IPO dan ditahan hingga tepat 3 tahun setelah perusahaan tersebut IPO.

Penelitian juga menghitung $\mathrm{BHRi}_{24}$ dan $\mathrm{BHRi}_{12}$ dari sampel penelitian untuk melihat apa yang terjadi pada periode jangka waktu yang lebih pendek dari 3 tahun.

Formula BHRi $\mathrm{BH}_{24}$ : 


$$
B H R i_{24}=\prod_{t=1}^{24}\left(1+r_{i t}\right)
$$

Formula BHRi $\mathrm{B}_{12}$ :

$$
B H R i_{12}=\prod_{t=1}^{12}\left(1+r_{i t}\right)
$$

c) Ukuran penawaran sebagai variabel kontrol merupakan jumlah dana yang didapatkan oleh perusahaan dari IPO dengan cara mengukur shares outstanding dikalikan dengan offer price.

d) Indikator industri adalah variabel dummy yang menyesuaikan perbedaan siklus bisnis dengan angka 1 adalah untuk industri yang memiliki Wealth Relative paling besar dan paling kecil, yaitu health care sebagai industri dengan Wealth Relative paling besar dan finance sebagai industri dengan Wealth Relative paling kecil.

e) Growth expectation dari sebuah perusahaan yang dilihat dari rasio Earnings/Price dan Book/Price dari perusahaan pada saat hari perdagangan pertama juga digunakan sebagai variabel kontrol, mengikuti penelitian Zheng dan Stangeland (2007).

f) Sesuai penelitian dari Degeorge dan Zeckhauser (1993) yang dikutip oleh Jai dan Kini (1994), salah satu alasan perusahaan melakukan IPO adalah untuk mengurangi rasio utang, sehingga rasio DER juga dimasukkan sebagai variabel kontrol penelitian

\section{Alat Analisis Data dan Pengujian}

Pengukuran performa saham perusahaan pada periode setelah IPO menggunakan metode Buy and Hold Return per bulan dengan periode 3 tahun dari saat IPO dengan variabel independen initial return perusahaan dan 4 variabel kontrol: (i) ukuran dari penawaran dan (ii) indikator industri (iii) growth expectation, dan (iv) debt to equity ratio. Metode cross-sectional regression digunakan untuk 


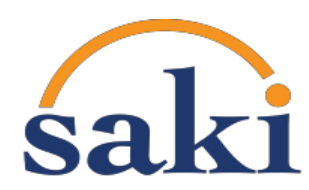

menjelaskan hubungan variabel dependen dan independen. Berdasarkan definisi operasional variabel maka didapat model untuk pengujian ini sebagai berikut:

$$
B H R i_{t}=\beta_{0}+\beta_{1} I R_{i}+\beta_{2} P R C D_{i}+\beta_{3} F I N_{i}+\beta_{4} H C_{i}+\beta_{5} D E R_{i}+\beta_{6} E P_{i}+\beta_{7} B M V_{i}
$$

BHR atau buy and hold return sebagai variabel dependen, IR adalah Initial Return dari hari pertama perdagangan saham sebagai variabel independen. Sisanya adalah variabel kontrol yang terdiri dari PRCD adalah Proceed atau besar penawaran, FIN dan HC adalah variabel dummy untuk industri yang didapat dari hasil perhitungan Wealth Relative, DER adalah debt-to-equity ratio dari perusahaan, EP adalah variabel kontrol earnings / price ratio perusahaan, dan BMV juga adalah variabel kontrol book value / price ratio perusahaan yang mewakili growth expectation perusahaan tersebut yang akan tercermin dalam harga sahamnya.

Sebelum itu, untuk memenuhi asumsi klasik, pengujian multikolinearitas, heteroskedastisitas, dan auto-kolerasi juga akan dilakukan.

\section{Hasil dan Pembahasan}

Setelah mengumpulkan data dari Bloomberg terminal, data yang didapatkan disortir sesuai dengan kriteria yang telah disebutkan di bagian Teknik Pengumpulan Data. Data yang diikutsertakan adalah perusahaan-perusahaan yang melakukan IPO di antara tahun 2004 sampai 2014. Selain itu, penulis tidak mengikutsertakan perusahaan-perusahaan yang tidak memiliki data yang lengkap (variabel dependen, variabel independen, dan variabel kontrol). Data yang tidak lengkap dicoba dilengkapi dengan menggunakan Yahoo! Finance, namun jika masih tidak tersedia, maka sampel tersebut dianggap tidak valid dan tidak dikutsertakan. Setelah mensortir data, didapatkan sebanyak 105 perusahaan yang memenuhi kriteria.

Berikut ada lah ringkasan dari data yang dimiliki dikelompokkan berdasarkan tahun perusahaan melakukan penawaran umum terbuka: 
Tabel 1. Ringkasan Data berdasarkan Tahun Penawaran Umum Terbuka

\begin{tabular}{|r|r|r|}
\hline \multicolumn{1}{|c|}{ Year } & No of IPOs & Avg. Initial Return \\
\hline 2004 & 5 & 0.0850 \\
\hline 2005 & 3 & 0.1096 \\
\hline 2006 & 9 & 0.3733 \\
\hline 2007 & 4 & 0.1455 \\
\hline 2008 & 9 & 0.1571 \\
\hline 2009 & 4 & 0.0671 \\
\hline 2010 & 16 & 0.2136 \\
\hline 2011 & 16 & 0.1260 \\
\hline 2012 & 13 & 0.1630 \\
\hline 2013 & 17 & 0.2020 \\
\hline 2014 & 9 & 0.1963 \\
\hline
\end{tabular}

Dari tahun 2004 sampai 2014, perusahaan yang melakukan penawaran umum terbuka dalam sampel ratarata memiliki initial return yang bernilai pos itif. Mengacu pada tabel tersebut, penawaran umum terbuka paling banyak terjadi pada tahun 2010 dan 2011 yaitu sebanyak 16 penawaran umum terbuka masingmasing tahun. Sedangkan, initial return paling besar terjadi pada pada tahun 2006 yaitu sebesar 37.3\%. Hal ini terutama disebabkan oleh PT Central Proteina Primba, Tbk. yang mengalami initial return sebesar 68.2\%. Sebaliknya, initial return paling kecil terjadi pada tahun 2009. Meskipun tidak ada kejadian yang mencatatkan initial return yang negatif pada tahun ini, perusahaan-perusahaan yang melakukan penawaran umum terbuka mengalami initial return yang bernilai kecil. Penulis juga melakukan pengelompokkan data berdasarkan sektor dari setiap perusahaan sebagai berikut:

Tabel 2. Ringkas an Data be rdasarkan Sek tor Perusahaan

\begin{tabular}{|l|r|r|}
\hline \multicolumn{1}{|c|}{ Sector } & No. of Stocks & Avg Initial Return \\
\hline Consumer & 29 & $16 \%$ \\
\hline Energy & 12 & $13 \%$ \\
\hline Financials & 21 & $22 \%$ \\
\hline Health Care & 1 & $7 \%$ \\
\hline Industrials & 22 & $21 \%$ \\
\hline Information Technology & 1 & $-1 \%$ \\
\hline Materials & 11 & $20 \%$ \\
\hline Real Estate & 4 & $6 \%$ \\
\hline Telecommunication Services & 4 & $32 \%$ \\
\hline
\end{tabular}




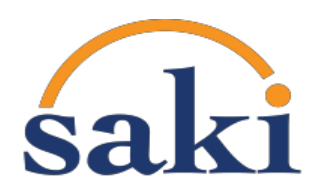

Berdasarkan tabel di atas, melihat dari level sektor, sebagian besar perusahaan memiliki initial return yang positif ketika melakukan penawaran umum terbuka. Initial return yang terjadi pada setiap sektor berbeda-beda, berkisar dari $-1 \%$ sampai $32 \%$. Sebagian besar sektor memiliki nilai initial return yang positif. Hal ini sejalan dengan penemuan penelitian terdahulu yang mendokumentasikan adanya fenomena initial return bernilai positif pada saat penawaran umum terbuka. Hanya terdapat satu sektor yang memiliki rata-rata initial return yang negatif, yaitu information technology. Namun, hal ini belum tentu dapat menggambarkan karakteristik dari sektor tersebut karena hanya terdapat satu sampel perusahaan dari sektor information technology dalam penelitian ini.

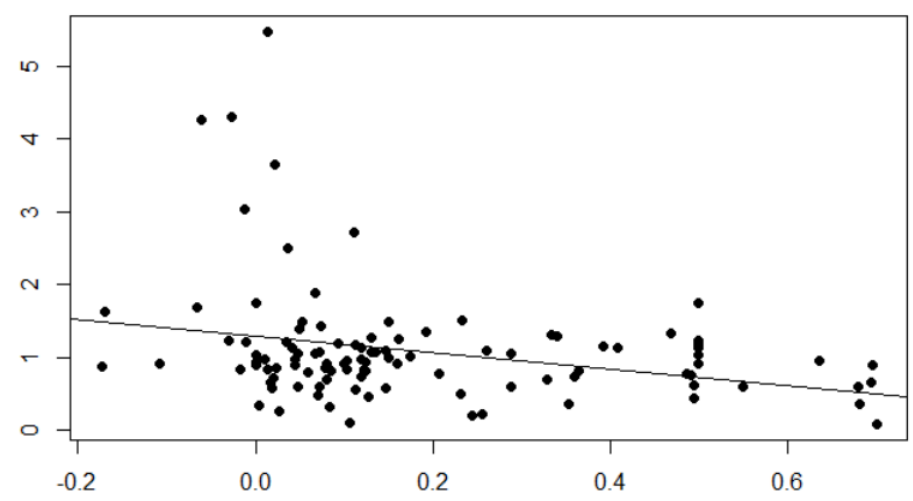

Grafik 1. Plot Initial Return terhadap Buy and Hold Return 3 Tahun

Plot dari data yang dikumpulkan ditampilkan pada Grafik 1. Terdapat hubungan yang negatif antara variabel independen yaitu initial return dengan variabel dependen yaitu buy and hold return selama 3 tahun. Dengan tujuan untuk lebih memahami karakteristik data yang dimiliki, penulis menampilkan ringkasan statistik deskriptif dari setiap variabel: 
Tabel 1. Ringkas an Statistik Deskriptif

\begin{tabular}{|c|r|r|r|r|r|}
\hline Variabel & \multicolumn{1}{|c|}{ N } & \multicolumn{1}{c|}{ Min } & \multicolumn{1}{c|}{ Max } & \multicolumn{1}{c|}{ Mean } & Std. Dev \\
\hline BHR36 & 105 & 0.090 & 5.479 & 1.108 & 0.824 \\
\hline Initial Return & 105 & -0.173 & 0.700 & 0.182 & 0.207 \\
\hline Proceeds & 105 & 100100 & 31457997 & 4084767 & 5578669 \\
\hline
\end{tabular}

Buy and hold return selama 3 tahun sebagai variabel dependen memiliki rata-rata 1.108. Hal ini berarti perusahaan-perusahaan yang termasuk dalam sampel untuk penelitian rata-rata memiliki return yang positif (diukur dengan buy and hold return) karena memiliki nilai buy and hold return lebih dari 1. Meskipun demikian, standar deviasi dari variabel ini cukup besar. Hal ini juga dapat terlihat pada Grafik 1. Sebagian kecil data memiliki return yang sangat besar.

Kemudian, variabel independen yaitu initial return memiliki karakteristik yang mirip dengan buy and hold return karena standar deviasi yang tergolong besar relatif terhadap rata-rata dari data yang dimiliki. Lalu nilai minimum untuk sampel initial return memiliki nilai negatif dan nilai maksimum memiliki nilai positif. Dari sini dapat diketahui bahwa dari sampel yang dimiliki, beberapa perusahaan memiliki harga penutupan pada hari IPO yang lebih rendah dibandingkan dengan offer price-nya dan perusahaan yang lain memiliki harga penutupan yang lebih tinggi. Meskipun demikian, rata-rata dari variabel ini bernilai positif yang dapat diartikan sebagai sebagian besar data memiliki initial return yang positif.

Sedangkan untuk variabel kontrol yaitu proceeds, terlihat bahwa terdapat range yang besar. Seperti yang sudah diungkapkan sebelumnya, proceeds digunakan untuk memasukkan efek dari ukuran perusahaan. Dari statistik deskriptif yang telah disajikan, sampel yang dimiliki penulis memiliki ukuran yang beragam.

\section{Wealth Relative}

Wealth relative adalah sebuah ukuran performa yang membandingkan performa saham (dilihat dari return selama 3 tahun) dengan benchmark yang ditentukan. Wealth relative dihitung dengan menggunakan rumus: $(1+$ average return saham-saham IPO selama 3 tahun $) /(1+$ average return dari 
benchmark). Dalam penelitian ini, benchmark yang dipilih sebagai pembanding adalah JCI Index. Berikut adalah rangkuman dari penghitungan wealth relative dari masing-masing sektor berdasarkan sistem GICS.

Tabel 2. Wealth Relative dari se tiap Sektor

\begin{tabular}{|l|r|r|r|}
\hline \multirow{2}{*}{ Sector } & \multicolumn{2}{c|}{ Average Growth } & Wealth Relative \\
\cline { 2 - 4 } & \multicolumn{1}{c|}{ Stocks } & \multicolumn{1}{c|}{ IHSG } & \\
\hline Consumer & 1.2665 & 1.4537 & 0.8712 \\
\hline Energy & 3.4327 & 1.5444 & 2.2226 \\
\hline Financials & 1.1309 & 1.4544 & 0.7776 \\
\hline Health Care & 2.5279 & 1.1171 & 2.2629 \\
\hline Industrials & 1.1780 & 1.3747 & 0.8569 \\
\hline Information Technology & 1.3699 & 1.2525 & 1.0938 \\
\hline Materials & 1.0394 & 1.3045 & 0.7968 \\
\hline Real Estate & 1.1683 & 1.2742 & 0.9169 \\
\hline Telecommunication Services & 1.2899 & 1.3603 & 0.9482 \\
\hline
\end{tabular}

Interpretasi dari nilai wealth relative ini penting agar dapat membandingkan performa efek dengan performa benchmark yaitu JCI Index. Ketika nilai dari wealth relative lebih dari 1, maka pada periode yang sama, perusahaan-perusahaan yang melakukan penawaran umum berhasil mencetak return yang lebih tinggi dibandingkan dengan benchmark. Sebaliknya, ketika nilai wealth relative kurang dari 1, performa perusahaan yang melakukan penawaran umum perdana lebih buruk dibandingkan benchmark. Dari hasil yang disajikan, dapat dilihat bahwa hanya sektor energy, health care, dan information technology yang memiliki return lebih tinggi dibandingkan dengan benchmark.

Penghitungan wealth relative ini juga berguna untuk penentuan dummy variable dalam regresi. Sejalan dengan Ritter (1991), sektor yang diberikan nilai 1 sebagai dummy variable adalah variabel yang memiliki wealth relative tertinggi dan terendah. Dalam kasus penelitian, kedua sektor tersebut adalah health care (tertinggi) dan financials (terendah).

\section{Analisis Regresi}

Penelitian bertujuan untuk menganalisis pengaruh besarnya initial return terhadap performa jangka panjang dari perusahaan yang diukur dengan buy and hold return selama 3 tahun setelah melakukan IPO. Untuk itu, penulis melakukan regresi majemuk dengan tingkat confidence interval sebesar 95\%. Berikut adalah hasil dari analis is regresi: 
Tabel 3. Ringkasan Hasil Regresi Initial Return terhadap Buy and Hold Return selama 3 tahun setelah IPO

\begin{tabular}{|l|r|r|r|r|}
\hline & Coefficients & Std. Error & t Stat & P-value \\
\hline Intercept & 1.2177 & 0.2247 & 5.4183 & 0.0000 \\
\hline Initial Return & -0.9798 & 0.4009 & -2.4440 & 0.0164 \\
\hline Proceeds & $7.7071 \mathrm{E}-09$ & 0.0000 & 0.5040 & 0.6154 \\
\hline Financials & 0.0774 & 0.2084 & 0.3715 & 0.7111 \\
\hline Health Care & -0.0346 & 0.8058 & -0.0429 & 0.9659 \\
\hline Debt to Equity Ratio & -0.0007 & 0.0010 & -0.6495 & 0.5176 \\
\hline Earnings/Price & 4.2962 & 1.7646 & 2.4347 & 0.0168 \\
\hline Book Value/Price & -0.3183 & 0.2675 & -1.1899 & 0.2371 \\
\hline
\end{tabular}

R-square: $15.48 \%$

BHR36 =1.2177 $-0.9798($ Initial Return $)+7.707 e-09$ (Proceeds $)+0.0774($ Financials $)-0.0346($ Health Care) - 0.0007(Debt to Equity Ratio) + 4.2962 (Earnings/Price) - 0.3183 (Book Value/Price)

Hasil regresi tersebut sejalan dengan penelitian terdahulu, dengan temuan yaitu initial return memiliki pengaruh negatif terhadap price growth dari saham tersebut, dapat terlihat dari tanda negatif pada koefisien initial return yang bersifat signifikan ( $p$-value sebesar 0.0048). Hal ini berarti semakin besar tingkat initial return saat IPO dari suatu saham, semakin buruk juga performa jangka panjang efek tersebut. Hasil regresi menunjukkan R-square sebesar $15.48 \%$ yang berarti model regresi tersebut memiliki kemampuan sebesar $15.48 \%$ dalam menjelaskan variasi pada variabel dependen berdasarkan variabel independen dan variabel kontrol secara keseluruhan.

Ritter (1991) menyediakan dua penjelasan terhadap fenomena initial return yang positif. Pertama dari sisi investor, terjadi market overreaction yang membuat harga penutupan di hari pertama menjadi terlalu tinggi. Seperti yang dinyatakan pada bab kajian literatur, overreaction terjadi ketika investor memiliki reaksi yang berlebihan terhadap informasi baru sehingga dalam kasus ini, investor menjadi terlalu optimis terhadap prospek suatu perusahaan yang baru melakukan penawaran umum terbuka. Kedua, peneliti mengambil sudut pandang perusahaan. Peneliti berargumen bahwa perusahaan melakukan 


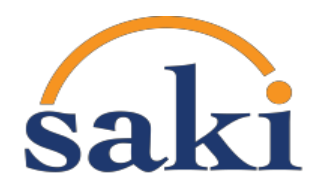

penawaran umum terbuka ketika melihat windows of opportunity. Kondisi ini diasosiasikan dengan kondisi ekonomi yang baik, market yang sedang optimis, dan lain-lain. Hal ini juga menjadi penyebab initial return yang bernilai positif pada penutupan hari pertama perdagangan.

Seiring berjalannya waktu, informasi mengenai sebuah perusahaan, terutama perusahaan yang baru melakukan IPO akan semakin tersedia kepada market (investor) dan harga dari suatu efek akan terkoreksi ke nilai wajarnya. Saham-saham yang dipandang paling positif oleh investor pada penawaran umum terbuka akan mendapatkan permintaan yang besar yang menyebabkan kenaikan pada harga saham tersebut dan initial return yang positif. Dalam kata lain, harga yang terbentuk pada hari pertama perdagangan menjadi terlalu tinggi dan ketika informasi tentang perusahaan tersebut semakin tersedia, akan terjadi koreksi pada harga dan pada kasus ini, koreksi yang terjadi adalah harga saham tersebut menurun. Sebaliknya, perusahaan yang dianggap tidak berprospek (dilihat dengan initial return yang mendekati 0) justru memiliki performa jangka panjang yang re latif baik relatif terhadap perusahaan yang dianggap memiliki prospek yang baik. Hal inilah yang menyebabkan hubungan yang terbalik antara initial return dengan performa jangka panjang perusahaan.

Proceed, sebagai variabel kontrol dalam penelitian ini juga sejalan dengan penelitian terdahulu yang dilakukan. Proceed memiliki koefisien dengan nilai positif yang berarti semakin besar uang yang didapatkan ketika penawaran umum, semakin bagus performa jangka panjang perusahaan. Hal ini dapat terjadi karena perusahaan-perusahaan yang mendapatkan proceeds yang besar diidentikan dengan perusahaan yang besar dan berkualitas baik yang artinya perusahaan-perusahaan ini menanggung risiko yang lebih kecil sehingga memiliki performa jangka panjang yang lebih baik. Meskipun demikian, ketika dilihat lebih jauh, variabel ini memiliki koefisien yang sangat kecil dan tidak bersifat signifikan. Hal ini dapat dilihat dari p-value variabel yang bernilai 0.845 (do not reject HO).

Hasil regresi juga membuktikan bahwa Debt to Equity Ratio sebagai variabel kontrol lainnya juga tidak bersifat signifikan terhadap performa jangka panjang perusahaan dilihat dari $p$-value sebesar 0.5176 (do not reject HO). Koefisien yang negatif berarti semakin besar DER dari sebuah perusahaan setelah 


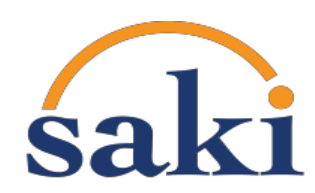

IPO, semakin buruk performa jangka panjang perusahaan tersebut. Hal itu berarti perusahaan gagal menurunkan rasio utang dari perusahaan melalui proses IPO.

Sedangkan rasio Earnings/Price menunjukkan koefisien yang positif dengan signifikan dilihat dari p-value sebesar 0.0168 (reject HO). Hal ini menunjukkan bahwa sustainable growth rate perusahaan yang dilihat dari rasio EP berhubungan pos itif dengan performa jangka panjang suatu perusahaan. Namun di lain sisi rasio Book Value / Price gagal dalam menjelaskan performa perusahaan dalam jangka panjang, dilihat dari $p$-value sebesar 0.23 (do not reject $\mathrm{HO}$ ) yang berarti variabel $\mathrm{BP}$ tidak bersifat signifikan terhadap model regresi.

Penulis kemudian juga ingin melihat hubungan initial return dengan buy and hold return selama 12 bulan dan 24 bulan. Berikut adalah hasil regresi initial return beserta variabel kontrol terhadap buy and hold return selama 12 bulan dan 24 bulan:

Tabel 4. Ringkasan Hasil Regresi Initial Return te rhadap Buy and Hold Return selama 1 tahun setelah IPO

\begin{tabular}{|l|r|r|r|r|}
\hline & Coefficients & Std. Error & $\boldsymbol{t}$ Stat & P-value \\
\hline Intercept & 0.6399 & 0.4112 & 1.5561 & 0.1230 \\
\hline Initial Return & 1.0685 & 0.7275 & 1.4687 & 0.1452 \\
\hline Proceeds & $-5.42 \mathrm{E}-09$ & 0.0000 & -0.1832 & 0.8551 \\
\hline Financials & -0.7563 & 0.3770 & -2.0059 & 0.0477 \\
\hline Health Care & 0.8456 & 1.4604 & 0.5790 & 0.5640 \\
\hline Debt to Equity Ratio & -0.0015 & 0.0019 & -0.8075 & 0.4214 \\
\hline Earnings/Price & 14.9074 & 3.9165 & 3.8063 & 0.0002 \\
\hline Book Value/Price & 0.1438 & 0.7067 & 0.2034 & 0.8392 \\
\hline
\end{tabular}

R-square: $22.80 \%$

BHR12 $=0.6399+1.0685$ (Initial Return) $-5.42 \mathrm{e}-09$ (Proceeds $)-0.7563$ (Financials $)+0.8456($ Health

Care) - 0.0015(Debt to Equity Ratio) + 14.9074 (Earnings/Price) + 0.1438 (Book Value/Price)

Pada jangka waktu satu tahun setelah IPO, hasil regresi tidak menunjukkan hasil yang sama dengan periode 3 tahun. Initial return memiliki koefisien positif namun tidak dapat menje laskan BHR12 secara signifikan karena memiliki nilai $p$-value sebesar 0.123 (do not reject $H O$ ) atau tidak signifikan. 


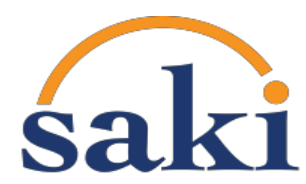

Variabel lain seperti proceeds, $D E R$, dan $B P$ juga tidak menunjukkan hasil yang signifikan dilihat dari nilai $p$-value. Hanya variabel EP yang menunjukkan hasil yang signifikan dengan $p$-value 0.0002 dan koefis ien positif 14.90 , yang berarti pada tahun pertama hanya variabel $E P$ yang memiliki pengaruh signifikan terhadap BHR12.

Tabel 5. Ringkasan Hasil Regresi Initial Return terhadap Buy and Hold Return selama 2 tahun setelah IPO

\begin{tabular}{|l|r|r|r|r|}
\hline & Coefficients & Std. Error & t Stat & P-value \\
\hline Intercept & 0.6830 & 1.3590 & 0.5026 & 0.6164 \\
\hline Initial Return & 0.3614 & 2.4041 & 0.1503 & 0.8808 \\
\hline Proceeds & $-2.7 \mathrm{E}-08$ & 0.0000 & -0.2766 & 0.7827 \\
\hline Financials & -1.4736 & 1.2460 & -1.1827 & 0.2399 \\
\hline Health Care & 1.2204 & 4.8262 & 0.2529 & 0.8009 \\
\hline Debt to Equity Ratio & -0.0084 & 0.0062 & -1.3518 & 0.1797 \\
\hline Earnings/Price & 51.2809 & 12.9426 & 3.9622 & 0.0001 \\
\hline Book Value/Price & -1.4817 & 2.3355 & -0.6344 & 0.5273 \\
\hline
\end{tabular}

R-square: $19.36 \%$

BHR12 $=0.6830+0.3614$ (Initial Return) $-2.7 \mathrm{e}-08$ (Proceeds) -1.4736 (Financials) +1.2204 (Health Care) - 0.0084 (Debt to Equity Ratio) + 51.2809 (Earnings/Price) - 1.4817 (Book Value/Price)

Sedangkan pada jangka waktu dua tahun setelah IPO, hasil regresi juga belum menunjukkan hasil yang sama dengan periode 3 tahun. Initial return memiliki koefisien positif yang semakin mengecil namun tetap tidak dapat menjelaskan BHR24 secara signifikan karena memiliki nilai $p$-value sebesar 0.6164 (do not reject $\mathrm{HO}$ ).

Variabel lain seperti proceeds, $D E R$, dan $B P$ juga tidak menunjukkan hasil yang signifikan dilihat dari nilai $p$-value masing-masing variabel. Hanya variabel EP yang kembali menunjukkan hasil yang signifikan dengan p-value 0.0001 dan koefisien positif 51.28, yang berarti pada tahun pertama hanya variabel $E P$ yang memiliki pengaruh signif ikan terhadap BHR 12.

Hal ini sejalan dengan penelitian terdahulu yang menyatakan dibutuhkan waktu jangka panjang untuk dapat melihat dampak negatif dari initial return terhadap performa BHR dari sebuah perusahaan 
karena adanya asymmetric information di pasar. Hal ini menyebabkan diperlukan waktu untuk harga saham terkoreksi atau mendekati fair value dan berdasarkan penemuan ini, diperlukan setidaknya 36 bulan sampai harga saham kembali pada harga wajarnya.

Di sisi lain dari kedua hasil tersebut, penelitian di jangka waktu satu dan dua tahun memiliki Rsquare yang relatif lebih baik dibandingkan dengan regresi initial return terhadap buy and hold return selama 3 tahun.

\section{Simpulan}

Fenomena initial return merupakan fenomena yang sering terjadi pada kasus penawaran umum terbuka. Pertanyaan-pertanyaan seputar alasan terjadinya initial return dan implikasinya terhadap performa perusahaan seringkali muncul. Penelitian ini ingin mengeksplorasi hubungan initial return dengan performa jangka panjang perusahaan yang diukur menggunakan buy and hold return selama 3 tahun di Bursa Efek Indonesia. Setelah melakukan analis is regresi, penulis menemukan bahwa terdapat hubungan yang negatif antara initial return dengan buy and hold return selama 36 bulan setelah melakukan penawaran umum terbuka.

Hal ini sejalan dengan penelitian terdahulu yang dilakukan. Alasan terjadinya hal ini adalah terjadi market overreaction dan perusahaan yang mengambil windows of opportunity sehingga harga penutupan di hari pertama berada di atas harga wajarnya. Seiring berjalannya waktu, informasi tentang suatu perusahaan semakin tersedia dan investor akan melakukan adjustment terhadap informasi baru. Pada tahap inilah koreksi terhadap harga saham akan terjadi dan saham-saham yang dianggap paling berprospek ketika penawaran umum terbuka (dilihat dengan initial return yang tinggi) justru memiliki return yang lebih kecil bahkan dalam sebagian kasus, negatif. Penelitian ini juga menemukan bahwa diperlukan waktu setidaknya 36 bulan untuk harga saham terkoreksi pada nilai wajarnya. Hal ini dapat dilihat dari hasil regresi buy and hold return selama 12 bulan dan 24 bulan yang memiliki koefisien yang tidak signifikan untuk variabel initial return. 


\section{Referensi}

Allen dan Faulhaber. (1988). Signalling by Underpricing in the IPO Market. Journal of Financial Economics, 23, 303-323

Boussaidi, Ramzi. (2013). Overconfidence Bias and Overreaction to Private Information Signals: The Case of Tunisia. Procedia - Social and Behavioral Sciences, 81, 241-245

Cai \& Wei. (1997). The investment and operating performance of Japanese initial public offerings. Pacific-Basin Finance Journal, 5, 389-417

Chorruk \& Worthington. (2010). New Evidence on the Pricing and Performance of Initial Public Offerings in Thailand, 1997-2008. Emerging Markets Review, 11, 285-299

Corhay, dkk. (2002). The Long Run Performance of Malaysian Initial Public Offerings (IPO): Value and Growth Effects. Journal of Managerial Finance, 28, 52-65

De Bondt dan Thaler. (1985). Does the Stock Market Overreact?. The Journal of Finance,. 40, 793-805

De Bondt dan Thaler. (1986). Further Evidence on Investor Overreaction and Stock Market Seasonality. The Journal of Finance, 42, 557-581

Fuadillah dan Harjito. (2009). Long-Run IPO Performances and Its Influencing Factors: The Case of Indonesian Stock Exchange. Jurnal Siasat Bisnis, 13, 151-171

Grinblatt \& Hwang. (1989). Signalling and the Pricing of New Issues. The Journal of Finance, 44 (2), $393-420$

Guo, Lev, dan Shi. (2005). Explaining the Short and Long-Term IPO Anomalies in the US by R\&D. Journal of Business Finance and Accounting, 33, 550-579

Ibbotson, dkk. (1988). Initial Public Offerings. Journal of Applied Corporate Finance, 1, 37-45

Jai dan Kini. (1994). The Post-Issue Operating Performance of IPO Firms. The Journal of Finance, 49. $1699-1726$

Levis, Mario. (1993). The Long-Run Performance of Initial Public Offerings: The UK Experience 19801988. Financial Management, 22, 28-41

Mahardhini dan Agus. (2009). Long-Run IPO Performances and Its Influencing Factors: The Case of Indonesian Stock Exchange. Jurnal Siasat Bisnis, 13, 151-171

Myers dan Majluf. (1984). Corporate Financing and Investment Decisions when Firms have Information that Investors do not have. Journal of Financial Economics, 13, 187-221

Pagano, dkk. (1998). Why do Companies Go Public? An Empirical Analysis. The Journal of Finance, 53, 27-64

Reber dan Vencappa. (2015). Deliberate premarket underpricing and aftermarket mispricing: New Insights on IPO Pricing. International Review of FInancial Analysis, 44, 18-33.

Ritter, Jay R. (1991). The Long Run Performance of Initial Public Offerings. The Journal of Finance, 46, 3-27

Raharja, dkk. (2017). Research of the Stock Price Overreaction and Investor Overconfidence Issues. Vilnius Gediminas Technical University, 1, 127-139

Sehgal and Singh. (2008). Determinants of Initial and Long-Run Performance of IPOs in Indian Stock Market. Asia Pacific Business Review, 4 (4), 24-37.

Sekaran. (2006). Metodologi untuk Bisnis. Terjemahan. Salemba Empat. Jakarta

Sutiono. (2015). Profil Perekonomian Indonesia, Retrieved May 30, 2018, from https://bppk.kemenkeu.go.id/id/publikasi/artike1/150-artikel-keuangan-umum/21178-profilperekonomian-indonesia.

Suyatmi dan Sujadi. (2006). Faktor-faktor yang Mempengaruhi Underpricing pada Penawaran Umum Perdana di Bursa Efek Jakarta. Benefit Jurnal Manajemen dan Bisnis, 10, 11-32

Vong and Trigueiros. (2010). The Short-Run Price Performance of Initial Public Offerings in Hong Kong: New Evidence. Global Finance Journal, 21, 253-261. 
Wadhwa, dkk. (2016). IPOs and SEOs, real investments, and market timing: Emerging market evidence. Journal of International Financial Markets, Institutions \& Money, 45, 21-41.

Welch. (1989). Seasoned Offerings, Imitation Costs, and the Underpricing of Initial Public Offerings. The Journal of Finance, 44 (2), 421-449.

Zheng dan Stangeland. (2007). IPO Underpricing, Firm Quality, and Analyst Forecasts. Financial Management, 36 (2), 45-64. 


\section{Lampiran}

\section{Analisis Uji Asumsi Klasik}

Uji Multikolinearitas BHR36

\section{Tabel Uji Multikolinearitas BHR36}

\begin{tabular}{|lcr|}
\hline Model & $\begin{array}{l}\text { Collinearity } \\
\text { Tolerance }\end{array}$ \\
\hline Initial Return & 0.897 & 1.115 \\
\hline Proceeds & 0.852 & 1.174 \\
\hline Debt to Equity Ratio & 0.948 & 1.054 \\
\hline Earnings / Price & 0.861 & 1.162 \\
\hline Book Value / Price & 0.988 & 1.012 \\
\hline
\end{tabular}

Berdasarkan tabel diatas, penulis menguji multikolinearitas dari data. Besar VIF dari data sebagian besar berada di sekitar 1 . Dengan data VIF $<10$, maka dapat dis impulkan tidak terjadi gangguan multikolinearitas dari sampel.

Uji Heteroskedastisitas BHR36

Grafik Scatte rplot Model BHR36

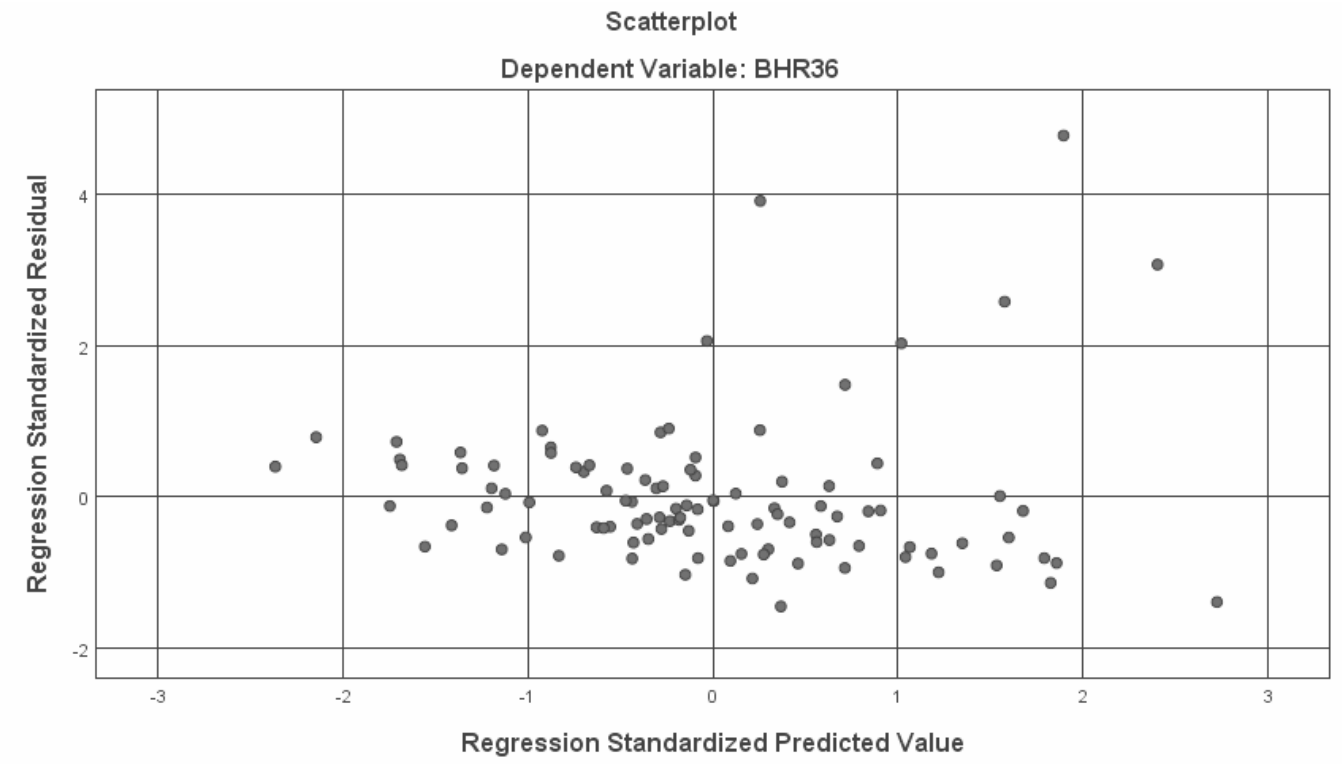


Untuk menguji heteroskedastisitas dari sampel, penulis melihat grafik scatterplot dari model. Terlihat bahwa data menyebar pada garis nol tanpa membentuk pola tertentu, sehingga bisa disimpulkan data bebas heteroskedastisitas.

Uji Multikolinearitas BHR24

Tabel Uji Multikolinearitas BHR24

\begin{tabular}{|lcr|}
\hline Model & \multicolumn{2}{c|}{$\begin{array}{l}\text { Collinearity } \\
\text { Tolerance }\end{array}$} \\
\hline Initial Return & 0.891 & 1.123 \\
\hline Proceeds & 0.736 & 1.358 \\
\hline Debt to Equity Ratio & 0.952 & 1.050 \\
\hline Earnings / Price & 0.551 & 1.814 \\
\hline Book Value / Price & 0.483 & 2.072 \\
\hline
\end{tabular}

Berdasarkan tabel diatas, penulis menguji multikolinearitas dari data. Besar VIF dari data sebagian besar berada di sekitar 1 . Dengan data VIF <10, maka dapat dis impulkan tidak terjadi gangguan multikolinearitas dari sampel.

Uji Heteroskedastisitas BHR24 


\section{Grafik Scatte rplot Model BHR24}

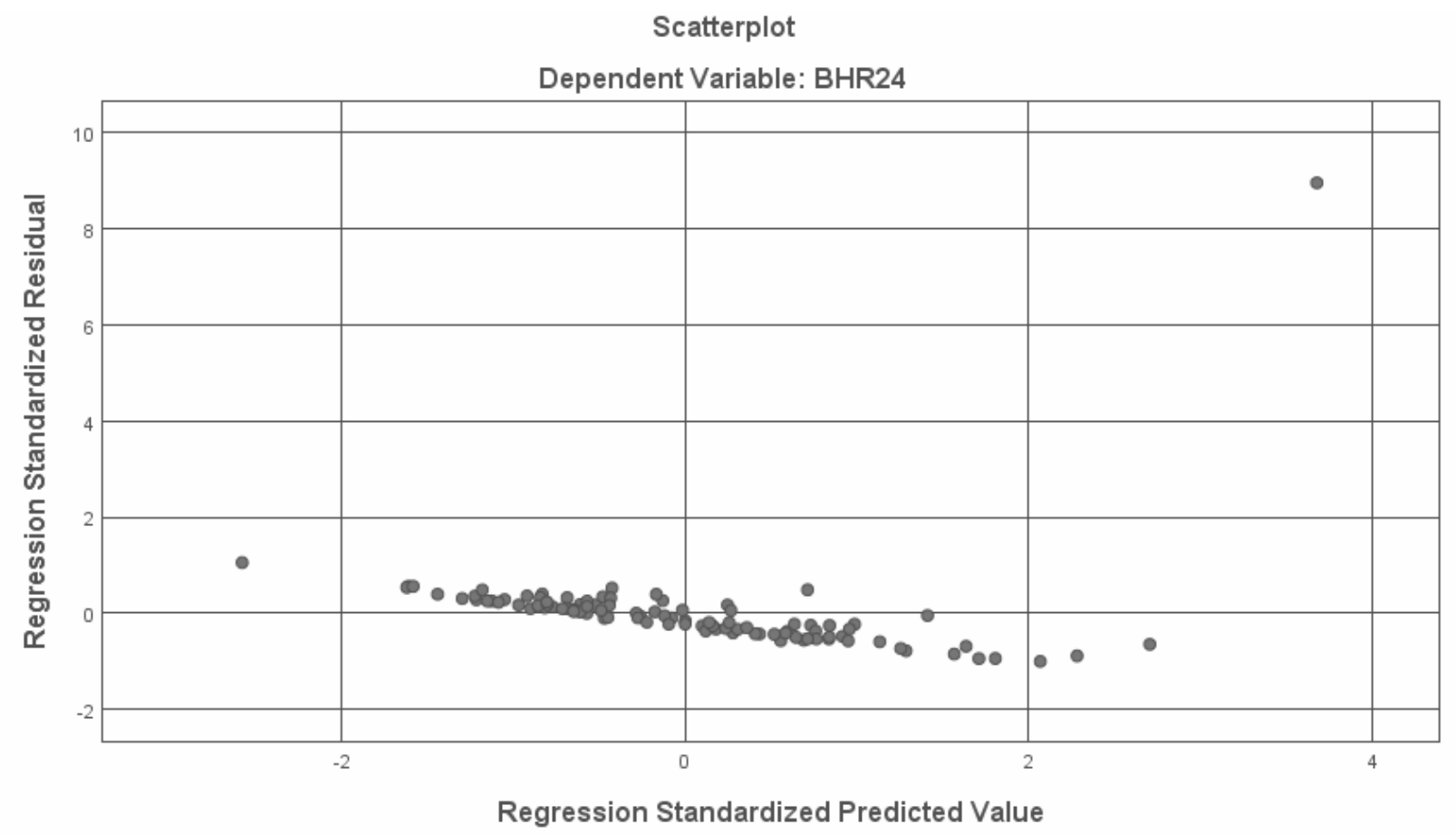

Untuk menguji heteroskedastis itas dari sampel, penulis melihat grafik scatterplot dari model.

Terlihat bahwa data menyebar pada garis nol tanpa membentuk pola tertentu, namun terlihat ada beberapa outlier dari data. Bisa disimpulkan data bebas heteroskedastisitas.

Uji Multikolinearitas BHR12

Tabel Uji Multikolinearitas BHR12

\begin{tabular}{|lcr|}
\hline Model & \multicolumn{2}{c|}{$\begin{array}{l}\text { Collinearity } \\
\text { Tolerance }\end{array}$} \\
\hline Initial Return & 0.891 & 1.123 \\
\hline Proceeds & 0.736 & 1.358 \\
\hline Debt to Equity Ratio & 0.952 & 1.050 \\
\hline Earnings / Price & 0.551 & 1.814 \\
\hline Book Value / Price & 0.483 & 2.072 \\
\hline
\end{tabular}

Berdasarkan tabel diatas, penulis menguji multikolinearitas dari data. Besar COllinearity Tolerance dan VIF BHR12 sama dengan BHR24. Besar VIF dari data sebagian besar berada di sekitar 1. Dengan data VIF <10, maka dapat disimpulkan tidak terjadi gangguan multikolinearitas dari sampel. 


\section{Uji Heteroskedastisitas BHR12}

\section{Grafik Scatte rplot Model BHR12}

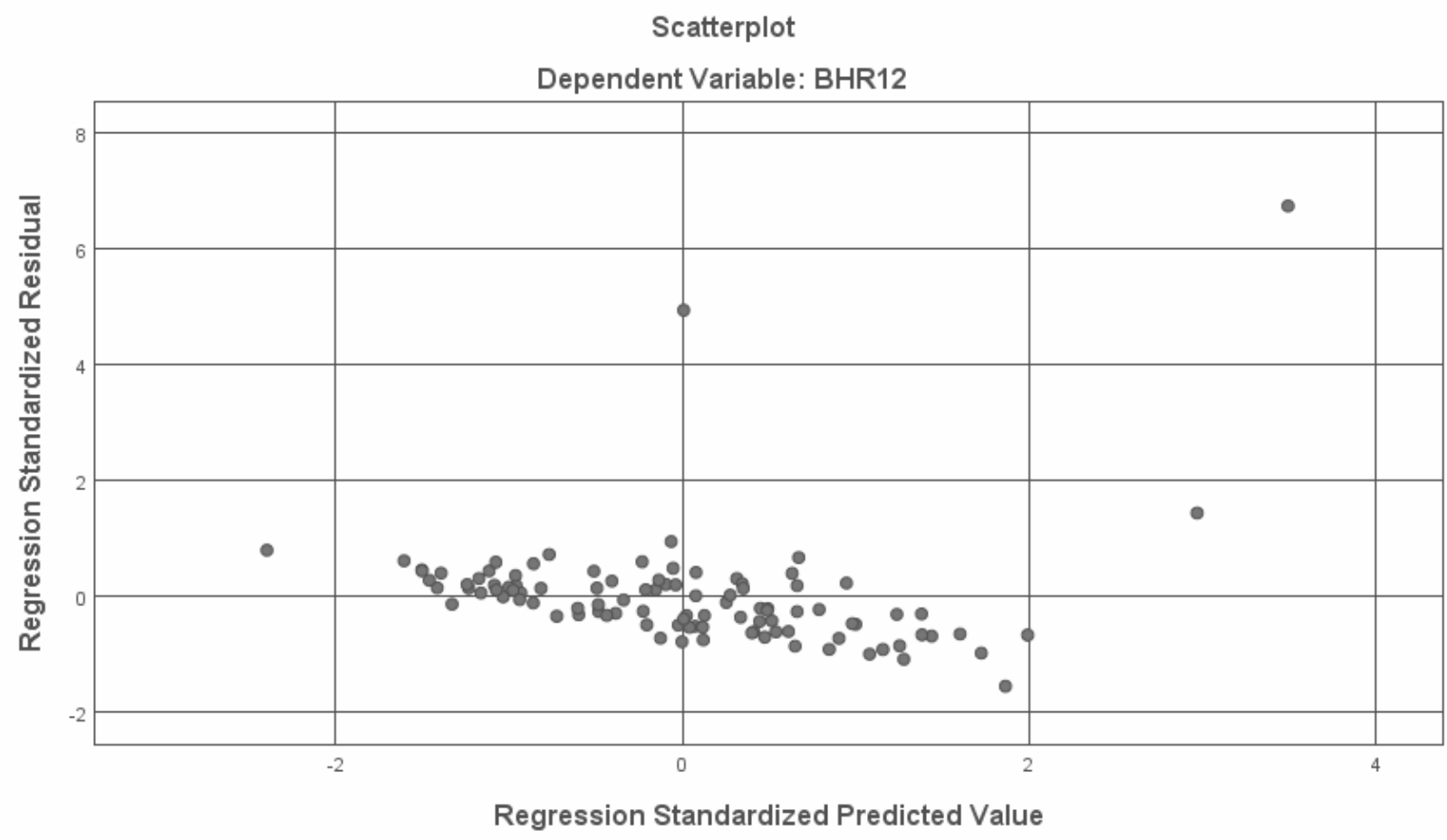

Untuk menguji heteroskedastisitas dari sampel, penulis melihat grafik scatterplot dari model.

Terlihat bahwa data menyebar pada garis nol tanpa membentuk pola tertentu, namun terlihat ada beberapa outlier dari data. Bisa disimpulkan data bebas heteroskedastisitas. 